artigo $]$

Jornalista graduado pela Universidade Federal do Paraná (UFPR).

Doutorando em Comunicação e Semiótica (PUC-SP), tem dois

mestrados, um em Comunicação, Educação e Administração, e outro

em Educação. É docente do curso de Jornalismo do Centro Universitário

Adventista de São Paulo (Unasp) e diretor de Jornalismo da Rádio Unasp.

E-mail: dargan_holdorf@hotmail.com

\title{
O sentido das mãos no futebol: figuratividade política e social
}

\section{The meaning of hands in soccer: political and social figurativity}

[resumo] Ao verificar a gestualidade das mãos dos jogadores de futebol, contempla-se a presença de elementos que expressam sentido além da comunicação limitada à prática esportiva, figurativizando ações políticas, sociais e culturais. Fazendo uso da semiótica discursiva, podem-se considerar alguns embates entre seleções nas copas do mundo como a dimensão relacional de um destinador forte sobre um destinatário fraco, provocando efeito de sentido que extrapola o campo de jogo. Neste artigo, apresentam-se três recortes, cujos confrontos futebolísticos representam sentidos que ultrapassam o contexto das quatro linhas das arenas.

\section{palavras-chave}

semiótica das mãos; figuratividade; gestualidade; futebol; copa do mundo.

[abstract] When we check the gestuality of hands of soccer players, we can note the presence of elements which are able to express meanings besides the communication limited to the sport practice, figuring political, social, and cultural actions. By using the discursive semiotics, it is possible to consider some rivalries between some soccer teams in world cups like a relational dimension of a strong destinator regarding a weak destinee, thus causing an effect of meaning that overpasses the soccer field. In this paper, three cuttings are presented, and their soccer confrontations represent meanings that surpass the context of four lines of an arena.

[key words] hand semiotics; figurativity; gestuality; soccer; world cup. 
São rarissimas as pesquisas semióticas a respeito das mãos. Destacamos os estudos de Bernard Lamizet (2004), Herman Parret (1983), este com poucos fragmentos sobre o tema, e Ana Claudia de Oliveira (1992), uma contribuição para a melhor compreensão das expressões gestuais do corpo. Todavia, como ressalta Oliveira, continua aberta a rota de interpretação para os pesquisadores, pois a pluridimensionalidade das mãos favorece esse olhar na atuação humana.

Tratando-se de um amplo assunto, é necessário delimitá-lo. A gestualidade das mãos pode dar os mais diversos significados aos efeitos de sentido percebidos nas nuances figurativas. Levantar o braço e balançar a mão ora para a direita, ora para a esquerda tem o seu sentido, assim como elevar a mão e levantar o dedo médio. Um cumprimento com a força da mão também depende do movimento dos olhos. Os elementos táteis se unem aos visuais. Para se analisar as mãos não há como desprezar o restante do corpo e seu caráter sinestésico. Eles se complementam como sujeitos.

Entretanto, a mão pode apresentar muito mais do que simples sensações superficiais. Detendo-se em Greimas (2002), o outro é apreendido pelos sentidos, por uma força estésica. A tatilidade conecta as fraturas greimasianas pelo arrebatamento, pela fascinação, pelas mãos cruzadas, pela volição e pelo toque em si.

No futebol, o uso da mão é quase exclusivo do goleiro. Contudo, como se constrói o sentido e o que ele figurativiza quando um jogador de linha gesticula com as mãos? Além dos sentidos convencionais direcionados à emoção da comemoração de um gol, de gestos obscenos, de protesto, de alerta aos companheiros ou mesmo de um lance fortuito, percebe-se, em muitos casos em que as mãos se projetaram no cenário de uma Copa do Mundo, a presença de elementos conotativos vinculados a questões de ordem política, social e econômica. Se a semiótica não tem mais contornos precisos e se distribui num extenso espaço cultural, de acordo com Raúl Dorra (2002) esse se torna um momento vantajoso para seu aprofundamento em campos ainda não explorados pelos semioticistas.

A pesquisa desenvolvida por Franciscu Sedda (2009) estimulou a organização deste estudo, no entanto, sob a perspectiva da utilização das mãos em copas do mundo e seus efeitos de sentido, e não da expressão 
corporal em sua totalidade. Ressaltam-se, aqui, três recortes: o primeiro com o inglês Alf Ramsey; o segundo com Pelé; e o último com o argentino Diego Maradona. Até parece que ninguém gosta dos vizinhos argentinos. Rivais de brasileiros, eles se tornaram inimigos históricos dos ingleses. Os dois exemplos iniciais sintonizam essa tendência patêmica quando eles se enfrentam nas copas do mundo. Ramsey foi o técnico da Inglaterra na Copa de 1966, e Maradona ocupou a função de capitão de sua equipe durante a Copa do México, em 1986, ambos sujeitos de ação. 0 recorte escolhido para Pelé marca o auge da carreira dele e a figurativização de sua performance gestual tátil.

\section{As mãos sancionadoras}

Enquanto a bandeira inglesa, pendurada na estaca de escanteio, recebia o afago do capitão da seleção da Argentina, Antonio Rattín, os súditos da rainha se sentiam ultrajados pela disforia causada pelo jogador argentino. Depois de uma avaliação axiológica, o árbitro, sujeito-destinador, analisa a ação e o sanciona negativamente por meio da expulsão. A partir de então, procedimentos manipuladores de provocação e intimidação tentam exercer o poder de um sobre o outro.

Argentina e Inglaterra se enfrentaram quatro anos antes, no Chile, e os ingleses levaram vantagem. Agora, em casa, os ingleses encaram uma das mais fortes candidatas ao título. 0 estado de tensão é visível, pois a peleja se desenvolve com muita violência de ambas as partes. Indignado com a truculência britânica, Rattín protesta, dirigindo-se em espanhol ao árbitro alemão. Nessa época ainda não existiam os cartões amarelo, de advertência, e o vermelho, de expulsão. Os gestos bruscos de um argentino falando provocam um acidente na percepção do árbitro, e ele interpreta o palavrório como expressões agressivas e ofensivas. A ruptura entre sujeito e objeto constrói esse momento estésico pregnante, isto é, repleto com o sentido da exclusão de Rattín.

0 jogador argentino não precisa compreender as palavras em alemão para deduzir que o árbitro o expulsara de campo. Revoltado, ele caminha lentamente, gesticulando contra a decisão irrefletida e precipitada do alemão. Ao chegar à bandeirinha de linha de fundo, uma bandeira inglesa, ele segura nas mãos o pano e, em seguida, sinaliza com a mão direita, em direção à torcida local, o sinal de que os argentinos estavam sendo "roubados", que o alemão favorecia os anfitriões de sua majestade. Tudo isso diante da corte inglesa, estarrecida nos camarotes do Estádio de Wembley, em Londres.

A ação de Rattín ao movimentar os dedos da mão direita, começando pelo mindinho até o indicador, provoca a ira da torcida adversária. Ela compreende o sentido do ato e o interpreta como uma afronta. Sancionado, Rattín demonstra volição em querer manipular os demais companheiros pela tentação a abandonarem a partida. Intimidados pelo destinador-manipulador, eles debreiam, afastando-se 
do sujeito-manipulador Rattín e preparando-se em direção à sua performance.

Depois do embate, vencido pelos donos da casa, argentinos e ingleses procuram selar a paz com o simples gesto da troca de camisas. Ao perceber tal atitude, o técnico Alf Ramsey dispara em direção a dois atletas e tenta impedir com as mãos a permuta das camisas nacionais. Com a mão esquerda ele segura o jogador Bobby Charlton e com a direita ele agarra a camisa, puxada na outra ponta por um argentino. Este segura com a mão direita a camisa argentina que seria entregue ao inglês, e com a mão esquerda ele estica a camisa inglesa, ainda presa ao punho esquerdo de Charlton e tomada pelo sujeito-sancionador.

Verificam-se aqui cinco mãos sancionadoras: a de Rattín agride o senso comum de transparência e honestidade num torneio desse calibre; a do árbitro que gesticula para o argentino se retirar de campo; a de Charlton ao contrariar todas as expectativas, provocando o encontro do inesperado, procurando a reconciliação com os adversários; a do outro jogador argentino querendo trocar sua imagética e simbólica camisa com a camisa de Charlton; e a de Ramsey tencionando coibir o concerto de amizade entre argentinos e ingleses.

A plástica tátil de Rattín figurativiza na memória argentina o domínio inglês sobre as Ilhas Malvinas, invadida desde 1833. A figuratividade é percebida nos protestos da torcida inglesa ao não aceitar que o império de sua majestade seja considerado um invasor, ladrão, espoliador. Charlton quer entregar sua camisa para o argentino, que deseja ardentemente recuperar ao menos esse símbolo diante da derrota. Contudo, Ramsey não abre mão de nada, assim como os ingleses não pretendem devolver as Malvinas, chamadas por eles de Ilhas Falklands. 0 árbitro reflete a mão do destinador, mediador implacável cuja solução favorece os vizinhos de continente, sancionando com a punição os rebeldes nativos sul-americanos.

\section{A mão que grita}

Nenhum desportista ficou tão ligado à imagem de seu país quanto Edson Arantes do Nascimento, o Pelé, em relação ao Brasil. Eleito como "Atleta do Século", Pelé se transformou em referencial para praticantes de diversas categorias esportivas e, inclusive, como símbolo de superação para outras atividades profissionais. Além de sua performance, com e sem a bola, Pelé passou a ser um ícone do atleta sem vícios, pois não fumava e não ingeria bebidas alcoólicas. Sua marca registrada: um salto em direção à torcida e, antes de tocar o gramado, o movimento do braço e a mão cerrada soqueando o ar.

Neste curto espaço, pretende-se visualizar duas cenas que permanecem no imaginário dos brasileiros. $\mathrm{Na}$ Copa de 1970, no México, Brasil e Itália disputam a final. Um dos dois conquistaria seu tricampeonato mundial de futebol. 0 Brasil não tem mais Garrincha, o gênio das pernas tortas, e os italianos não sentem o gosto da vitória há 32 anos. 0 passado da era Mussolini, o desastre aéreo com o Torino, em 1949, e os sucessivos fracassos 
da azzurra no pós-guerra os incomodam, motivando 0 embate contra os brasileiros. Ambos os plantéis estão recheados de uma nova geração de craques, mas 0 Brasil ainda tem Pelé. De compleição física desprezível para os padrões atuais, sua baixa estatura não deveria assustar os altos zagueiros italianos, retrato dos legionários romanos, hoje gladiadores da pós-modernidade nos estádios do calcio.

Quando o ponta-esquerda Rivelino alça a bola para o lado esquerdo da pequena área italiana, Pelé e Burgnich saltam. Duas intenções contrárias. Burgnich tentando afastar a bola inimiga da área. Pelé procurando escorá-la, ou quem sabe acariciá-la, para só então despachá-la para o fundo das redes. Zagueiro, atacante e bola acompanhados pelo goleiro Albertosi. Todos sob os apreensivos olhares dos companheiros, do público torcedor, das testemunhas neutras e dos milhões de telespectadores.

Pelé sabe que Burgnich é mais alto. Se pulasse nas costas de Burgnich, não haveria muita chance de a bola passar e Pelé cabecear. Então, Pelé se antecipa e atira seu corpo ao alto, à frente do "gladiador", projetando-se para atingir a bola que descreve uma parábola em alta velocidade. Como um beija-flor, Pelé plana, permanece no ar um segundo, tempo suficiente para aguardar o desfecho, a chegada da pelota de cromáticos gomos pentagonais em preto e branco. Lembrando Thürlemann (2009), Pelé tem uma "perspectiva do alto", estuda o terreno, percebe a colocação de Albertosi entre as traves, a distância do gol e a velocidade necessária para que a bola toque as redes antes de ser interceptada.

0 ponto mais alto de seu voo cruza a transcendente bola com a imanente relação com o gol. Nesse eterno segundo, os "súditos" relembram um episódio anterior, semelhante, ocorrido no jogo contra os ingleses, quando a bola recebeu violenta cabeceada de "sua majestade", mas não transpôs a linha do gol, momento inesperado provocado pelo goleiro Gordon Banks. Um acidente no percurso do programado.

Albertosi estica o braço esquerdo e salta. Um foguete vence seus reflexos. A "vista do alto" entroniza Pelé na horizontalidade, e o certeiro e poderoso cabeceio em linha reta descendente faz a bola abraçar as redes. Burgnich desce e cai, olhando consternado para o abatido Albertosi, e a bola ainda quicando e girando dentro do gol. 0 arqueiro olha para a bola e soqueia 0 chão, sinal de raiva pelo esforço em vão, pela falha do confiável Burgnich diante do imprevisivel inimigo Pelé. 0 algoz patina suas chuteiras no gramado e, com um impulso, recupera o equilibrio e dispara em direção à multicolorida torcida mexicana. Seus companheiros o seguem correndo, mas, antes de o agarrarem, ele salta e soqueia o ar, o excedente de sentido da vitória sobre a pobreza, a violência, a discriminação, a arrogância dos poderosos, a superação de uma nação periférica sobre o Primeiro Mundo, a perspectiva de esperança para outros semelhantes a ele, o "rei", próximo da consagração e da coroação.

Depois do apito final não há tempo para correr 
para o vestiário. Uma multidão invade o gramado e despe "sua majestade". Dele se retiram a gloriosa camisa pátria, as meias, as chuteiras e até mesmo o calção, deixando-o apenas de cueca. Em sua cabeça colocam um sombreiro com as cores do México - vermelho, verde e branco. Ironicamente as mesmas cores da bandeira italiana - e o erguem sobre os braços e gritos da turba ensandecida. Ovacionado, o "rei" finalmente recebe a coroa. Agora ele não representa somente um povo, mas os devaneios de uma nação de miseráveis espalhados nos quatro cantos do planeta. Daí o sentido de despi-lo das cores da seleção canarinho. Ele não será mais um cidadão brasileiro, mas fará parte da nobreza mundial de desvalidos, e estes precisam com urgência de um "rei", um ícone a quem possam recorrer.

Dois anos antes, durante os Jogos Olímpicos na Cidade do México, dois atletas norte-americanos subiram ao pódio e, de luvas negras, ergueram os punhos cerrados em apoio ao movimento dos Panteras Negras, figuratividade da luta contra o fim da segregação étnica nos Estados Unidos. Punidos, eles perderam as medalhas conquistadas e foram banidos pelo Comitê Olímpico dos Estados Unidos. Na mesma cidade, Pelé não rouba a cena do jogo. 0 seu soco no ar dá sentido, mesmo que passageiro, à vida de milhões de marginalizados pelas "tropas legionárias opressivas" das elites, dos poderes políticos e econômicos. 0 soco equivale ao grito de liberdade dos súditos, clamor expresso no gol de Pelé, no derradeiro trilar do apito e na aclamação sob a "coroa mexicana".

\section{A mão vingadora}

Dezesseis centímetros diferenciam a altura do goleiro inglês Peter Shilton e a do maior fenômeno do futebol argentino Diego Maradona. A bola foi levantada para a área inglesa, descrevendo uma parábola em direção aos dois jogadores, Shilton e Maradona. Ambos tomam impulso e pulam sob os olhares expectantes das torcidas. Teoricamente, Shilton levaria vantagem sobre o nanico Maradona. Além de sua altura e melhor preparo para o salto, o goleiro poderia simplesmente erguer os braços e aumentar em mais um metro a distância em relação a seu opositor. Assim ele chegaria antes à bola. Entretanto, no próximo ato, a imprevisibilidade sustentaria a estesia.

Quatro anos antes, argentinos e ingleses guerreavam, não nos campos espanhóis da Copa do Mundo, mas no sul do Oceano Atlântico. Os primeiros lutando pela reconquista das Malvinas, e os segundos defendendo suas Falklands. Os soldados da idade de Maradona foram convocados. Ele escapou, recusou-se a abandonar os gramados para integrar as tropas ensandecidas e despreparadas rumo ao desconhecido. Se o regime militar argentino se perpetuasse no poder, certamente o sujeito Maradona receberia a sanção do Estado-destinador.

Os extasiados torcedores mexicanos vibram pelo sucesso argentino. Afinal, os brasileiros haviam sido eliminados, e agora eles precisam de outro sujeito referencial, que impeça a vitória imperialista nas terras 
do Novo Mundo. E o herói ressurge no efeito de sentido provocado novamente por um latino-americano. Em 1970, os ingleses, também derrotados pelos brasileiros comandados pela trupe de Pelé, ousaram intimidar os anfitriões ao levar para o México água e alimentos. Os ingleses demonstraram insegurança, e os mexicanos se sentiram ofendidos pela petulância e desrespeito. Arrogantes, os ingleses os afrontaram como colonizados. Os mexicanos perceberam que os ingleses ainda se consideravam dominadores, uma relação entre destinador forte e destinatário fraco, um encontro disfórico, o simulacro dos déspotas sobre os oprimidos, figuratividade dos tempos da escravidão e do espólio das colônias do império britânico.

Voltando à cena no estádio, Maradona tem consciência de suas limitações físicas em relação ao goleiro inglês. Uma coisa seria estar com a bola aos pés diante de Shilton, outra situação era saltar para tentar cabecear a bola. Pelé vencera Burgnich. É bem verdade que o zagueiro italiano não deveria usar as mãos. Mais alto que Maradona, Pelé conseguiria mais impulso do que Albertosi? Essas são conjecturas que não conduzem a nenhuma conclusão. Maradona seria tão genial a ponto de superar Shilton na impulsão e conseguir tocar a bola com a cabeça para o gol?

A bola desce rapidamente. Ambos saltam. Shilton estica ao máximo o braço direito com a mão fechada e a nítida intenção de soquear a bola. Não há qualquer possibilidade de Maradona evitar o rebote do goleiro. A jogada está perdida. De repente, o choque entre ambos. Os dois caem no gramado e Shilton não entende a reação súbita de um brado vitorioso do argentino. A bola beija a rede dentro do gol, e o estádio estremece. Shilton e outros jogadores ingleses correm para o árbitro e protestam. Maradona e seus companheiros comemoram. Algo está errado. Em um mesmo ato, o contraditório: disforia para uns, euforia para outros.

Antes de Shilton rechaçar a bola, Maradona ergue o braço esquerdo e toca na bola com a mão sujeito-vingador -, fazendo-a encobrir Shilton e se projetar para o gol. 0 sentido se constrói na imprevisibilidade das relações entre sujeitos e objeto. 0 toque da mão esquerda de Maradona figurativiza o dia da vingança, o grito abafado nas gargantas daqueles humilhados no passado, a volta por cima das mais trágicas situações e o recomeço de uma nova era. Ao descrever esse quadro, Eduardo Galeano (2009, p. 197) denomina o argentino de "messias convocado para redimir a maldição histórica dos italianos do sul", quando atuou pelo Napoli, e "vingador da derrota argentina na Guerra das Malvinas, mediante um gol velhaco e outro gol fabuloso" sobre os ingleses. Maradona se redime como "soldado" que havia negado seu posicionamento e compromisso como cidadão argentino durante a Guerra das Malvinas. 
Segundo os mais extremistas, a mão vingadora de Maradona figurativiza "la mano de Dios", referindo-se ao próprio craque portenho, idolatrado pela seita maradonista.

A mão vingadora alcança sua performance ao reparar a injustiça contra Rattín, ao celebrar junto aos mexicanos seu desprezo pelos nobres súditos da rainha Elizabeth II, ao devolver no campo de batalha da Copa a derrota nas Malvinas e ao efetivar Maradona como o novo "rei". Nasce o mito de um "Pelé" dos brancos argentinos, dos desafortunados de uma América hispânica perseguida, despojada e vilipendiada por décadas de governos ditatoriais.

\section{Considerações finais}

Se Greimas considera imperativo ampliar esse gênero de análises "ao conjunto de canais sensoriais" (2002, p. 74), então a pesquisa a respeito da semiótica das mãos se encaixa às propostas interpretativas da semiótica discursiva. Neste caso, pode-se verificar que a gestualidade plástica das mãos figurativiza mais do que singelos ícones comunicacionais e de tradições culturais.

Muito além de serem apenas membros da entidade corpórea, ferramentas biofísicas ou de convívio social, as mãos sofrem ações de natureza política de seu destinador. Elas podem ser a figuratividade da manipulação, da performance, da sanção e da esperança. Daí o desafio de se investigar essa manifestação estética em uma área aparentemente apolítica, como o futebol nos eventos de Copa do Mundo.

\section{REFERÊNCIAS}

DORRA, Raúl. Perspectiva da semiótica. In: GREIMAS, Algirdas Julien. Da imperfeição. São Paulo: Hacker, 2002, p. 113-124.

GALEANO, Eduardo. Futebol ao sol e à sombra. Porto Alegre: L\&PM, 2009.

GREIMAS, Algirdas Julien. Da imperfeição. São Paulo: Hacker, 2002.

LAMIZET, Bernard. Sémiotique de la main. Degrés, Bruxelas, v. 32, no 118, p. 1-16, 2004.

OLIVEIRA, Ana Claudia de. Fala gestual. São Paulo: Perspectiva, 1992.

PARRET, Herman. On believing: epistemological and semiotic approaches. De la croyance: approches épistémologiques et sémiotiques. Berlim/Nova York: De Gruyter, 1983.

SEDDA, Franciscu. Maradona e a explosão: o futebol entre visibilidade e imprevisibilidade. São Paulo, 3 dez. 2009. Conferência proferida no XV Colóquio do Centro de Pesquisas Sociossemióticas (CPS) da PUC-SP.

THÜRLEMANN, Felix. Regarder avec les oiseaux: sur la structure d'énonciation d'un type de carte géographique. Nouveaux Actes Sémiotiques, nº 112, 2009. Disponível em: <http://revues.unilim. fr/nas/document.php?id=2940 > . Acesso em: 7 out. 2009. 